\title{
The association between medication or alcohol use and the incidence of frailty: a retrospective cohort study
}

Janja Jazbar, Igor Locatelli and Mitja Kos ${ }^{*}$ id

\begin{abstract}
Background: Understanding potentially modifiable factors that influence the risk of frailty is a key concern for the management of this urgent contemporary public health challenge. This study evaluates the association between the use of various medications or alcohol and the incidence of frailty among older adults.

Methods: This study was a retrospective cohort study on older adults ( $\geq 65$ years) using data from the longitudinal Survey of Health, Ageing and Retirement in Europe (SHARE survey, 28 countries). Medication use was measured as taking several different groups of medications. Alcohol use was assessed with SHARE questions corresponding to AUDIT-C. The outcome measure was the incidence of frailty after two years, defined by frailty index (FI) and frailty phenotype (FP). A multiple logistic regression model was used to evaluate the association with adjustment for several potential confounding factors.
\end{abstract}

Results: Of the 14,665 FI-population participants, 1800 (12.3\%) developed frailty within two years. Of the 8133 FPpopulation participants, 2798 (34.4\%) developed pre-frailty and 247 (3.0\%) developed frailty within two years of baseline. After adjustment for potential confounding variables, non-hazardous alcohol use (adjusted OR; 95\% Cl for the Fl-population: $0.68 ; 0.60-0.77)$ and hazardous alcohol use $(0.80 ; 0.68-0.93)$ are associated with lower incidence of frailty compared to no alcohol use. The odds of frailty are increased when taking medications; the largest effect size was observed in older adults taking medication for chronic bronchitis (adjusted OR; $95 \% \mathrm{Cl}$ for the $\mathrm{Fl}$ population: $2.45 ; 1.87-3.22)$, joint pain and other pain medication $(2.26 ; 2.00-2.54)$, medication for coronary and other heart disease $(1.72 ; 1.52-1.96)$, medication for diabetes $(1.69 ; 1.46-1.96)$, and medication for anxiety, depression and sleep problems $(1.56 ; 1.33-1.84)$. Additionally, the risk of frailty was increased with stroke, Parkinson's disease and dementia.

Conclusions: Taking certain groups of medication was associated with increased incidence of frailty and pre-frailty, which might be due to either medication use or the underlying disease. Alcohol use was associated with a lower risk of pre-frailty and frailty compared to no alcohol use, which might be due to reverse causality or residual confounding. There was no significant interaction effect between medication groups and alcohol use on frailty incidence.

Keywords: Frailty index, Frailty phenotype, Longitudinal study, SHARE data, Medication use, Alcohol use

* Correspondence: mitja.kos@ffa.uni-lj.si

University of Ljubljana, Faculty of Pharmacy, Askerceva cesta 7, 1000

Ljubljana, Slovenia

(c) The Author(s). 2021 Open Access This article is licensed under a Creative Commons Attribution 4.0 International License, which permits use, sharing, adaptation, distribution and reproduction in any medium or format, as long as you give appropriate credit to the original author(s) and the source, provide a link to the Creative Commons licence, and indicate if changes were made. The images or other third party material in this article are included in the article's Creative Commons. licence, unless indicated otherwise in a credit line to the material. If material is not included in the article's Creative Commons licence and your intended use is not permitted by statutory regulation or exceeds the permitted use, you will need to obtain permission directly from the copyright holder. To view a copy of this licence, visit http://creativecommons.org/licenses/by/4.0/ The Creative Commons Public Domain Dedication waiver (http://creativecommons.org/publicdomain/zero/1.0/) applies to the data made available in this article, unless otherwise stated in a credit line to the data. 


\section{Background}

Frailty, a syndrome that is associated with old age, is among the most urgent contemporary public health challenges due to global trends of population aging [1]. Frailty can be characterized as a decline in the physiological capacity of multiple organ systems, leading to increased vulnerability to stressor events [1-3]. It is also associated with an increased risk of falls, fractures, hospitalization, institutionalization, impaired quality of life and mortality [2]. How to objectively measure frailty is extensively debated in the medical literature, with two main methods being widely recognized. The first method, 'frailty phenotype', defines frailty as the presence of at least three out of the following five physical components: shrinking, weakness, exhaustion, slowness and low levels of physical activity. Pre-frailty is defined as the presence of one or two of these five physical components [2, 4]. The second method defines a 'frailty index' as the accumulation of age-related deficits, taken from over thirty health deficits that include comorbidities, signs, symptoms, physiological factors and disabilities [2, 5].

Although frailty prevalence increases with age, it is not an inevitable result of aging [2]. Therefore, understanding potentially modifiable factors that influence the risk of frailty is a key concern for its management. The association between alcohol use and incident frailty remains controversial, with only four studies included in a recent meta-analysis [6]. Short-term studies suggest lower incidence of frailty with higher alcohol use [6], while recent long-term study reported higher incidence of frailty in old age with high alcohol use in mid-life [7]. Also, different disease or accompanying medication use have been associated with increased frailty, for example multiple sclerosis, diabetes, chronic obstructive pulmonary disease or taking antidepressant or psychotropic medications [8-11]. Nevertheless, no study so far comprehensively evaluated the risk of frailty in patients taking different pharmacotherapy groups of medication. Furthermore, alcohol has the potential to interact with medications, with possible harmful health outcomes, for example sedation, hypotension, hypoglycaemia or gastrointestinal bleeding [12]. The possible influence of this interaction on frailty has not yet been investigated.

The aim of our study was to evaluate the association between use of different medications or alcohol and the incidence of frailty in order to specify groups of older adults with higher risk of becoming frail.

\section{Methods}

\section{Study design}

This retrospective cohort study on older adults uses data from the longitudinal Survey of Health, Ageing and Retirement in Europe (SHARE survey). Data from 2013
(Wave 5) and 2015 (Wave 6) are used for the analysis $[13,14]$. Study exposures are disease, medication and alcohol use measured at baseline (2013, Wave 5). The outcome measure of the study is the incidence of frailty syndrome two years after baseline (2015, Wave 6).

\section{Study data}

The SHARE survey is a large-scale longitudinal and multidisciplinary study of over 140,000 individuals, aged 50 years and older, from 27 European countries and Israel (the SHARE survey countries). The first wave began in 2004 (Wave 1), and new waves are released approximately every two years; the most recent data from regular questionnaires were used in the current study (Waves 5 and 6). Detailed methodologies used in the SHARE survey are described elsewhere [15-18]. The SHARE survey is subject to continuous ethics review; Waves 5 and 6 were reviewed and approved by the Ethics Council of the Max Planck Society [19].

\section{Study population}

SHARE survey participants are aged 50 years and over at the time of sampling, and they all live in one of the SHARE survey countries. The inclusion criteria for the current study were: (i) participants in both 2013 and 2015 SHARE survey, and (ii) aged 65 years or more in 2013. This study population was formed of 25,225 individuals with a mean (SD) age of 73.8 (6.6) years, and of whom $55.5 \%$ were female and $44.5 \%$ were male. The study participants lived in the following countries: Austria, Germany, Sweden, Spain, Italy, France, Denmark, Switzerland, Belgium, Israel, Czech Republic, Luxembourg, Slovenia and Estonia. The final study analysis was restricted to participants who were classified as non-frail (using the two described frailty measures) at baseline (Wave 5, 2013) and who had complete datasets for all study variables at both the 2013 and 2015 timepoints. Thus, the final study analysis was performed on data from: (i) 14,665 participants who were classified as non-frail using the 'frailty index', and (ii) 8133 individuals who were classified as non-frail using the 'frailty phenotype'. The difference in absolute number of nonfrail participants according to each method is the consequence of three frailty categories according to 'frailty phenotype' (non-frail, pre-frail, frail) and two frailty categories according to 'frailty index' (non-frail, frail).

\section{Frailty measures}

The outcome measure in this study was frailty syndrome, as defined by two validated methods: frailty index and frailty phenotype.

Frailty phenotype (FP), first defined in 2001 by Fried et al., defines frailty syndrome as the presence of three or more of five pre-defined physical components: 
shrinking, weakness, exhaustion, slowness and low levels of physical activity [4]. We use the previously published operationalization of frailty phenotype (FP) on SHARE data in our study; details are presented in Additional file 1 [20-23]. This method has been validated in relation to different health outcomes, although we acknowledge the differences from the original method [20, 21]. Study participants were classified into the following groupings: (i) non-frail (robust) if none of the components were present; (ii) pre-frail if one or two of the components were present; and (iii) frail if three to five components were present.

Frailty index (FI), first defined in 2001 by Mitnitski et al., defines frailty syndrome through an accumulation of age-related deficits, which are typically taken from a list of at least thirty deficits [5]. Frailty index (FI) has also been defined previously using SHARE survey data from Waves 1 and 2 ('SHARE-FI') [21, 24]. In the current study, we adjusted the previously published SHARE-FI for use in data from Waves 5 and 6, in accordance with the guidelines published by Searle et al. [25] The age-related deficits from which the FI is calculated are listed in Additional file 2. In accordance with previous studies, participants with FI scores $\geq 0.25$ were considered to be frail $[21,26]$.

\section{Exposure measures}

Exposure to medications and the underlaying disease was evaluated through the question "Do you currently take drugs at least once a week for (health) problems mentioned on this card?", with the following medication groups: (i) high blood cholesterol, (ii) high blood pressure, (iii) coronary or cerebrovascular diseases and other heart diseases, (iv) diabetes, (v) joint pain or joint inflammation and other pain (e.g., headache, back pain, etc.), (vi) sleep problems, anxiety or depression, (vii) osteoporosis, (viii) stomach burns, (ix) chronic bronchitis, and (x) drugs for inflammation suppression (only glucocorticoids or steroids). Additionally, health status was further characterized by the following diseases not included in the medication list: stroke, cancer, Parkinson's disease, dementia (Alzheimer disease, dementia or other serious memory impairment), and cataracts; these were assessed using the following question: "Has a doctor ever told you that you had/Do you currently have any of the conditions on this card?"

Baseline alcohol use was assessed from SHARE survey data that were adapted to their equivalent in the AUDIT-C test. The following questions were used: (i) "During the last 3 months, how often have you drunk any alcoholic beverages, like beer, cider, wine, spirits or cocktails?", (ii) "In the last three months, on the days you drank, about how many drinks do you have?", (iii) "In the last three months, how often did you have six or more drinks on one occasion?". Answers to each question were categorized into 5 categories from 0 to 4 points. For each participant a total sum for all three questions was calculated and then categorized as follows: (i) no alcohol use (0 points), (ii) non-hazardous alcohol use (1-3 points in women and 1-4 points in men), or (iii) hazardous alcohol use ( $\geq 4$ point in women and $\geq 5$ points in men) [27]. Detailed method was published and validated previously [27-29].

\section{Covariates}

The study model included the following potential confounding factors: age, sex, country of residence, highest educational level, BMI and smoking (yes/no). Age was categorized as follows: (i) 65-74 years, (ii) 75-84 years, and (iii) $\geq 85$ years. Highest educational level was categorized based on ISCED 1997 coding into three categories: primary, secondary, tertiary. BMI was categorized into four groups: (i) < 18.5, (ii) $18.5-25$, (iii) $25-30$, and (iv) $>30$.

\section{Statistical analysis}

Multiple logistic regression model was used to evaluate the influence of medication and alcohol exposure at the 2013 baseline on the incidence of frailty syndrome two years later, in 2015. The two frailty measures, FI and FP, were used as the outcome measures in two separate analyses. All exposure variables and potential confounding variables were entered in the model concomitantly: alcohol use, medication use, stroke, cancer, Parkinson's disease, dementia, cataracts, age, sex, country of residence, BMI, highest educational level and smoking. Separate analyses were performed with the addition of the interaction effect between alcohol use and each specific medication group in the model.

\section{Results \\ Study population characteristics}

The final study populations, after excluding participants that had missing data, were 14,665 based on the FI (FIpopulation) and 8133 based on FP (FP-population); all the final study participants were considered to be nonfrail at baseline. Basic characteristics of both study populations are presented in Table 1 . The mean ages (SD) were 72.5 (6.0) years (FI-population) and 71.6 (5.4) years (FP-population). More than half of the study participants were non-hazardous alcohol users at baseline, with approximately one fifth being hazardous alcohol users (22.4 and 23.3\% for the FI- and FP-populations, respectively). No alcohol use at baseline was reported by $26.7 \%$ of the FI-population and $22.4 \%$ of the FP-population. At baseline, almost half of the study participants were taking medications for high blood pressure and approximately 1 in 4 had medications for high blood 
Table 1 Baseline characteristics of the study population. (FI-population $N=14,665$; FP-population $N=8133$ )

\begin{tabular}{|c|c|c|}
\hline \multirow[t]{2}{*}{ Baseline characteristic } & $\begin{array}{l}\text { Non-frail population at baseline based on } \\
\text { frailty index (FI-population) }\end{array}$ & $\begin{array}{l}\text { Non-frail population at baseline based on frailty } \\
\text { phenotype (FP-population) }\end{array}$ \\
\hline & $N=14,665$ & $N=8133$ \\
\hline \multicolumn{3}{|l|}{ Age group } \\
\hline $65-74$ years & $9870(67.3 \%)$ & $5979(73.5 \%)$ \\
\hline $75-84$ years & $4184(28.5 \%)$ & 1948 (24.0\%) \\
\hline$\geq 85$ years & $611(4.2 \%)$ & $206(2.5 \%)$ \\
\hline Mean (SD) & $72.5(6.0)$ & $71.6(5.4)$ \\
\hline \multicolumn{3}{|l|}{ Sex } \\
\hline Male & $7312(49.9 \%)$ & $4244(52.2 \%)$ \\
\hline Female & $7353(50.1 \%)$ & $3889(47.8 \%)$ \\
\hline \multicolumn{3}{|l|}{ Highest educational level } \\
\hline primary & $3258(22.2 \%)$ & $1584(19.5 \%)$ \\
\hline secundary & 7900 (53.9\%) & $4441(54.6 \%)$ \\
\hline tertiary & $3507(23.9 \%)$ & 2108 (25.9\%) \\
\hline \multicolumn{3}{|l|}{ Body mass index } \\
\hline under 18.5 & 149 (1.0\%) & $69(0.8 \%)$ \\
\hline $18.5-25$ & $5379(36.7 \%)$ & $3053(37.5 \%)$ \\
\hline $25-30$ & $6480(44.2 \%)$ & $3668(45.1 \%)$ \\
\hline above 30 & $2657(18.1 \%)$ & $1343(16.5 \%)$ \\
\hline No. of chronic diseases; Mean (SD) & $1.7(1.3)$ & $1.5(1.3)$ \\
\hline Smoking (yes) & $2120(14.5 \%)$ & 1129 (13.9\%) \\
\hline \multicolumn{3}{|l|}{ Alcohol use } \\
\hline no alcohol use & $3915(26.7 \%)$ & $1823(22.4 \%)$ \\
\hline nonhazardous & $7472(51.0 \%)$ & $4413(54.3 \%)$ \\
\hline hazardous & $3278(22.4 \%)$ & 1897 (23.3\%) \\
\hline Stroke (yes) & $392(2.7 \%)$ & $188(2.3 \%)$ \\
\hline Cancer (yes) & $694(4.7 \%)$ & $378(4.6 \%)$ \\
\hline Parkinson disease (yes) & $72(0.5 \%)$ & $34(0.4 \%)$ \\
\hline Cataracts (yes) & $1487(10.1 \%)$ & $820(10.1 \%)$ \\
\hline Dementia (yes) & $75(0.5 \%)$ & $31(0.4 \%)$ \\
\hline $\begin{array}{l}\text { Medication for high blood pressure } \\
\text { (yes) }\end{array}$ & $7090(48.3 \%)$ & 3830 (47.1\%) \\
\hline $\begin{array}{l}\text { Medication for coronary and other } \\
\text { heart disease (yes) }\end{array}$ & $2580(17.6 \%)$ & $1237(15.2 \%)$ \\
\hline Medication for high cholesterol (yes) & $3908(26.6 \%)$ & $2180(26.8 \%)$ \\
\hline Medication for diabetes (yes) & $1646(11.2 \%)$ & $877(10.8 \%)$ \\
\hline $\begin{array}{l}\text { Medication for joint pain and other pain } \\
\text { (yes) }\end{array}$ & 2645 (18.0\%) & $1125(13.8 \%)$ \\
\hline $\begin{array}{l}\text { Medication for anxiety, depression and } \\
\text { sleep problems (yes) }\end{array}$ & $1248(8.5 \%)$ & $521(6.4 \%)$ \\
\hline Medication for osteoporosis (yes) & $777(5.3 \%)$ & $378(4.6 \%)$ \\
\hline Medication for stomach burns (yes) & $1082(7.4 \%)$ & $522(6.4 \%)$ \\
\hline Medication for chronic bronchitis (yes) & $347(2.4 \%)$ & $140(1.7 \%)$ \\
\hline $\begin{array}{l}\text { Medication for suppresing inflammation } \\
\text { (yes) }\end{array}$ & $384(2.6 \%)$ & $163(2.0 \%)$ \\
\hline
\end{tabular}


cholesterol. Between 10 and 20\% of the participants were taking medications for coronary and other heart disease, joint pain and other pain, and diabetes. The prevalence of other medication groups was less than 10\% among non-frail baseline participants.

\section{Frailty incidence}

Of the 14,665 FI-population participants, 1800 (12.3\%) developed frailty within two years of baseline; the incidence of frailty increased considerably with baseline age and was higher among females. The incidence of frailty in the population that reported no baseline alcohol use was $18.8 \%$, whereas the incidence was lower in nonhazardous $(9.9 \%)$ and hazardous (10.0\%) alcohol users. FI-population participants with medications had a higher incidence of frailty compared to participants without specific medication group (Table 2). The highest incidence of frailty was reported in the participants taking medications for chronic bronchitis (25.1\%), joint pain and other pain medications (22.8\%) and medications for anxiety, depression and sleep problems (20.9\%).

Of the 8133 FP-population participants, 2798 (34.4\%) developed pre-frailty and $247(3.0 \%)$ developed frailty within two years of baseline. The incidences of prefrailty and frailty in the population that reported no baseline alcohol use were 40.9 and $4.7 \%$, respectively. The incidences were similarly lower in non-hazardous and hazardous alcohol users $(32.3 \%$ for pre-frailty in non-hazardous and $32.9 \%$ in hazardous alcohol users, and $2.4 \%$ for frailty in non-hazardous and $2.8 \%$ for frailty in hazardous alcohol users). Similar to the FIpopulation, older adults taking medications had higher incidences of pre-frailty and frailty, with the highest reported for medications for chronic bronchitis, joint pain and other pain medications and medications for anxiety, depression and sleep problems (Table 2). Only older adults taking medications for high blood cholesterol had slightly lower incidence of frailty (3.0\% compared to $3.1 \%$ in the population without these medications).

\section{Association between medication or baseline alcohol use, and frailty incidence}

After adjustment for potential confounding variables, both medication and baseline alcohol use show a statistically significant association with frailty incidence when measured by the FI, with odds ratios $(95 \% \mathrm{CI})$ presented in Table 2. Both non-hazardous and hazardous alcohol use are associated with lower odds of frailty incidence compared to no alcohol use. The odds for frailty are increased when taking medications, with significant difference (adjusted OR, 95\% CI) for medications for high blood pressure $(1.35,1.21-1.51)$, coronary and other heart disease $(1.72,1.52-1.96)$, diabetes $(1.69,1.46-$ $1.96)$, joint pain and other pain $(2.26,2.00-2.54)$, anxiety, depression and sleep problems (1.56, 1.33-1.84), osteoporosis (1.56, 1.27-1.93), chronic bronchitis (2.45, $1.87-3.22)$ and suppressing inflammation (1.54, 1.142.05).

In case of FP (Table 2), non-hazardous alcohol use is significantly associated with lower odds of pre-frailty and frailty compared to no alcohol use (adjusted OR, 95\% CI: $0.86,0.76-0.98$ for pre-frailty and 0.66, 0.470.93 for frailty). Hazardous alcohol use shows no significant difference compared to no alcohol use. Significantly increased odds for pre-frailty and frailty were confirmed for the following medication groups: high blood pressure $(1.15,1.04-1.28$ for pre-frailty and $1.37,1.02-1.84$ for frailty), coronary and other heart disease $(1.28,1.12-1.47$ for pre-frailty and $1.70,1.20-2.41$ for frailty), joint pain and other pain $(1.58,1.38-1.82$ for pre-frailty and 2.38 , 1.70-3.34 for frailty), anxiety, depression and sleep problems $(1.56,1.28-1.89$ for pre-frailty and $2.14,1.37-3.36$ for frailty), and chronic bronchitis (1.68, 1.17-2.42 for pre-frailty and $2.67,1.20-5.95$ for frailty). Additionally, taking medications for diabetes was significantly associated with frailty $(1.62,1.11-2.37)$ and taking medications for osteoporosis was significantly associated with prefrailty $(1.38,1.1-1.73)$. Taking medications for high blood cholesterol was significantly associated with lower odds for frailty $(0.68,0.49-0.95)$.

The interaction between each medication group and baseline alcohol use shows no statistically significant influence on frailty syndrome for either the FI-population or the FP-population (multiple logistic regression model with interaction terms; data not shown).

\section{Discussion}

The present study explores the complex relationship between medication and alcohol use and the incidence of frailty in a large cohort of older adults. The incidence of frailty in our study was increased in participants with various groups of medication and in participants with no alcohol use. There was no effect of interaction between medication and alcohol use on the incidence of frailty.

Older adults taking certain medications had increased risk of frailty and pre-frailty in our study, indicating which groups of older adults are at higher risk of developing frailty, either due to adverse effects of medication use or the underlying disease. The greatest effect size was observed in older adults taking medications for chronic bronchitis, medications for joint pain and other pain, medications for coronary and other heart disease, medications for diabetes, and medications for anxiety, depression and sleep problems in both FI- and FPpopulation. Among disease states, significant association with increased incident frailty was found in older adults with stroke (FI-population), Parkinson's disease (FI- and FP-population), dementia (FI-population), and cataracts 
Table 2 Association between alcohol use, medication use and frailty incidence in the multiple model

\begin{tabular}{|c|c|c|c|c|c|c|}
\hline \multirow[t]{2}{*}{ Variable } & \multicolumn{2}{|l|}{ Frailty index - frail } & \multicolumn{2}{|c|}{ Frailty phenotype - pre-frail } & \multicolumn{2}{|c|}{ Frailty phenotype - frail } \\
\hline & $\begin{array}{l}\text { Incidence of frailty } \\
\text { (FI) }\end{array}$ & $\begin{array}{l}\text { Adjusted OR } \\
(95 \% \mathrm{Cl})\end{array}$ & $\begin{array}{l}\text { Incidence of pre- } \\
\text { frailty (FP) }\end{array}$ & $\begin{array}{l}\text { Adjusted } \mathrm{OR}^{\mathrm{a}} \\
(95 \% \mathrm{Cl})\end{array}$ & $\begin{array}{l}\text { Incidence of frailty } \\
\text { (FP) }\end{array}$ & $\begin{array}{l}\text { Adjusted } \mathrm{OR}^{\mathrm{a}} \\
(95 \% \mathrm{Cl})\end{array}$ \\
\hline \multicolumn{7}{|l|}{ Age } \\
\hline $65-74$ years & $8.7 \%$ & Reference & $31.4 \%$ & Reference & $2.0 \%$ & Reference \\
\hline $75-84$ years & $18.0 \%$ & $2.10(1.87-2.36)^{* *}$ & $41.6 \%$ & $1.57(1.40-1.76)^{* *}$ & $4.8 \%$ & $2.33(1.71-3.17)^{* *}$ \\
\hline$\geq 85$ years & $30.4 \%$ & $5.23(4.25-6.45)^{* *}$ & $51.9 \%$ & $3.46(2.50-4.78)^{* *}$ & $16.0 \%$ & $17.0(10.1-28.7)^{* *}$ \\
\hline \multicolumn{7}{|l|}{ Sex } \\
\hline Male & $10.9 \%$ & Reference & $32.1 \%$ & Reference & $3.0 \%$ & Reference \\
\hline Female & $13.7 \%$ & $1.18(1.05-1.33)^{*}$ & $37.0 \%$ & $1.19(1.08-1.32)^{* *}$ & $3.1 \%$ & $1.07(0.79-1.45)$ \\
\hline \multicolumn{7}{|l|}{ Alcohol use } \\
\hline $\begin{array}{l}\text { No alcohol } \\
\text { use }\end{array}$ & $18.8 \%$ & Reference & $40.9 \%$ & Reference & $4.7 \%$ & Reference \\
\hline $\begin{array}{l}\text { Non- } \\
\text { hazardous }\end{array}$ & $9.9 \%$ & $0.68(0.60-0.77)^{* *}$ & $32.3 \%$ & $0.86(0.76-0.98)^{*}$ & $2.4 \%$ & $0.66(0.47-0.93)^{*}$ \\
\hline Hazardous & $10.0 \%$ & $0.80(0.68-0.93)^{*}$ & $32.9 \%$ & $0.93(0.80-1.08)$ & $2.8 \%$ & $0.88(0.58-1.32)$ \\
\hline \multicolumn{7}{|l|}{ Stroke } \\
\hline No & $11.9 \%$ & Reference & $34.3 \%$ & Reference & $3.0 \%$ & Reference \\
\hline Yes & $24.2 \%$ & $2.10(1.61-2.73)^{* *}$ & $40.4 \%$ & $1.22(0.88-1.68)$ & $5.9 \%$ & $1.82(0.89-3.74)$ \\
\hline \multicolumn{7}{|l|}{ Cancer } \\
\hline No & $12.2 \%$ & Reference & $34.4 \%$ & Reference & $3.1 \%$ & Reference \\
\hline Yes & $13.0 \%$ & $1.23(0.96-1.57)$ & $34,1 \%$ & $1.01(0.80-1.27)$ & $2.6 \%$ & $0.98(0.49-1.97)$ \\
\hline \multicolumn{7}{|c|}{ Parkinson's disease } \\
\hline No & $12.2 \%$ & Reference & $34.4 \%$ & Reference & $3.0 \%$ & Reference \\
\hline Yes & $34.7 \%$ & $4.29(2.48-7.43)^{* *}$ & $41.2 \%$ & $1.80(0.83-3.94)$ & $17.6 \%$ & $7.58(2.47-23.2)^{* *}$ \\
\hline \multicolumn{7}{|l|}{ Cataracts } \\
\hline No & $11.9 \%$ & Reference & $34.0 \%$ & Reference & $2.7 \%$ & Reference \\
\hline Yes & $15.2 \%$ & $1.12(0.95-1.33)$ & $37.7 \%$ & $1.13(0.96-1.33)$ & $6.2 \%$ & $2.07(1.43-3.01)^{* *}$ \\
\hline \multicolumn{7}{|l|}{ Dementia } \\
\hline No & $12.1 \%$ & Reference & $34.4 \%$ & Reference & $3.0 \%$ & Reference \\
\hline Yes & $38.7 \%$ & $3.97(2.34-6.72)^{* *}$ & $45.2 \%$ & $1.45(0.68-3.10)$ & $3.2 \%$ & $0.59(0.07-5.16)$ \\
\hline \multicolumn{7}{|c|}{ Med. for high blood pressure } \\
\hline No & $9.6 \%$ & Reference & $31.9 \%$ & Reference & $2.3 \%$ & Reference \\
\hline Yes & $15.2 \%$ & $1.35(1.21-1.51)^{* *}$ & $37.3 \%$ & $1.15(1.04-1.28)^{*}$ & $3.8 \%$ & $1.37(1.02-1.84)^{*}$ \\
\hline \multicolumn{7}{|c|}{ Med. for coronary and other heart disease } \\
\hline No & $10.6 \%$ & Reference & $33.1 \%$ & Reference & $2.6 \%$ & Reference \\
\hline Yes & $20.1 \%$ & $1.72(1.52-1.96)^{* *}$ & $41.4 \%$ & $1.28(1.12-1.47)^{* *}$ & $5.3 \%$ & $1.70(1.20-2.41)^{*}$ \\
\hline \multicolumn{7}{|c|}{ Med. for high blood cholesterol } \\
\hline No & $11.5 \%$ & Reference & $33.9 \%$ & Reference & $3.1 \%$ & Reference \\
\hline Yes & $14.3 \%$ & $1.08(0.96-1.22)$ & $35.6 \%$ & $0.93(0.83-1.05)$ & $3.0 \%$ & $0.68(0.49-0.95)^{*}$ \\
\hline \multicolumn{7}{|c|}{ Med. for diabetes } \\
\hline No & $11.5 \%$ & Reference & $34.1 \%$ & Reference & $2.8 \%$ & Reference \\
\hline Yes & $18.6 \%$ & $1.69(1.46-1.96)^{* *}$ & $37.1 \%$ & $1.11(0.95-1.30)$ & $5.2 \%$ & $1.62(1.11-2.37)^{*}$ \\
\hline \multicolumn{7}{|c|}{ Med. for joint and other pain } \\
\hline No & $10.0 \%$ & Reference & $32.6 \%$ & Reference & $2.6 \%$ & Reference \\
\hline Yes & $22.8 \%$ & $2.26(2.00-2.54)^{* *}$ & $45.9 \%$ & $1.58(1.38-1.82)^{* *}$ & $6.0 \%$ & $2.38(1.70-3.34)^{* *}$ \\
\hline
\end{tabular}


Table 2 Association between alcohol use, medication use and frailty incidence in the multiple model (Continued)

\begin{tabular}{|c|c|c|c|c|c|c|}
\hline \multirow[t]{2}{*}{ Variable } & \multicolumn{2}{|l|}{ Frailty index - frail } & \multicolumn{2}{|c|}{ Frailty phenotype - pre-frail } & \multicolumn{2}{|c|}{ Frailty phenotype - frail } \\
\hline & $\begin{array}{l}\text { Incidence of frailty } \\
\text { (FI) }\end{array}$ & $\begin{array}{l}\text { Adjusted } \mathrm{OR}^{\mathrm{a}} \\
(95 \% \mathrm{Cl})\end{array}$ & $\begin{array}{l}\text { Incidence of pre- } \\
\text { frailty (FP) }\end{array}$ & $\begin{array}{l}\text { Adjusted } \mathrm{OR}^{\mathrm{a}} \\
(95 \% \mathrm{Cl})\end{array}$ & $\begin{array}{l}\text { Incidence of frailty } \\
\text { (FP) }\end{array}$ & $\begin{array}{l}\text { Adjusted } \mathrm{OR}^{\mathrm{a}} \\
(95 \% \mathrm{Cl})\end{array}$ \\
\hline \multicolumn{7}{|c|}{ Med. for anxiety, depression and sleep problems } \\
\hline No & $11.5 \%$ & Reference & $33.5 \%$ & Reference & $2.8 \%$ & Reference \\
\hline Yes & $20.9 \%$ & $1.56(1.33-1.84)^{* *}$ & $47.4 \%$ & $1.56(1.28-1.89)^{* *}$ & $6.3 \%$ & $2.14(1.37-3.36)^{*}$ \\
\hline \multicolumn{7}{|c|}{ Med. for osteoporosis } \\
\hline No & $11.9 \%$ & Reference & $34.0 \%$ & Reference & $3.0 \%$ & Reference \\
\hline Yes & $19.2 \%$ & $1.56(1.27-1.93)^{* *}$ & $43.4 \%$ & $1.38(1.10-1.73)^{*}$ & $4.2 \%$ & $1.34(0.74-2.45)$ \\
\hline \multicolumn{7}{|c|}{ Med. for stomach burns } \\
\hline No & $11.9 \%$ & Reference & $34.0 \%$ & Reference & $3.0 \%$ & Reference \\
\hline Yes & $16.5 \%$ & $1.14(0.94-1.37)$ & $40.0 \%$ & $1.11(0.91-1.35)$ & $3.4 \%$ & $1.01(0.58-1.74)$ \\
\hline \multicolumn{7}{|c|}{ Med. for chronic bronchitis } \\
\hline No & $12.0 \%$ & Reference & $34.2 \%$ & Reference & $3.0 \%$ & Reference \\
\hline Yes & $25.1 \%$ & $2.45(1.87-3.22)^{* *}$ & $47.1 \%$ & $1.68(1.17-2.42)^{*}$ & $6.4 \%$ & $2.67(1.20-5.95)^{*}$ \\
\hline \multicolumn{7}{|c|}{ Med. for inflammation } \\
\hline No & $12.1 \%$ & Reference & $34.2 \%$ & Reference & $3.0 \%$ & Reference \\
\hline Yes & $17.4 \%$ & $1.54(1.14-2.05)^{*}$ & $44.2 \%$ & $1.32(0.94-1.85)$ & $4.9 \%$ & $1.61(0.70-3.66)$ \\
\hline
\end{tabular}

(FP-population). Our findings are consistent with study published in Lancet Public Health [30], which also reported high association of frailty with chronic obstructive pulmonary disease, diabetes, stroke, coronary heart disease, depression and pain among other long-term conditions. Our study confirms relationship between cognitive health and frailty, since older adults with medication for pain, anxiety, depression and sleep problems were at significantly increased risk of frailty. Although the theory of this association remains poorly explored, relationship between cognition and frailty was also confirmed in a systematic review [31]. Furthermore, certain central nervous system medications are related to falls [32], which might be either antecedents or manifestations of frailty [33]. Interestingly, in the FP-population reduced incidence of frailty was found in older adults taking high blood cholesterol medications. Due to the asymptomatic nature of hyperholesterolaemia, association to increased risk of frailty might be less expected, unless it was related to secondary cardiovascular outcomes. On the other hand some studies have shown association between statin use and improved physical performance [10]. Nevertheless, a prospective study of statin use and incident frailty in women showed no association [10]. The results of our study could also be explained by residual confounding not included in our model, therefore further studies are needed to explore this finding.

The effect of medications cannot be separated from the effect of the underlying disease in our study. The correlation between disease and corresponding medication use in our data was too high to include both variables in the model. Our study results thus indicate which groups of older adults are at higher risk of frailty and should be monitored more closely, but the causal mechanisms of frailty remain to be explored.

The influence of alcohol consumption on frailty risk is controversial. A few longitudinal studies show an inverse correlation between alcohol consumption and frailty risk [6, 34-37]. The results of the current study have similar implications. Non-hazardous and hazardous alcohol use in old age showed decreased frailty risk compared to no alcohol use, even after adjustment for baseline disease and medication use; however, hazardous alcohol use showed smaller decrease than non-hazardous alcohol use (adjusted OR (95\% CI): 0.68 (0.60-0.77) for nonhazardous use and $0.80(0.68-0.93)$ for hazardous alcohol use). Similarly, when using frailty phenotype as the outcome measure, only non-hazardous alcohol use was associated with decreased frailty incidence, suggesting a U-shaped relationship, which has been proposed before $[6,38,39]$. Sub-analysis of our data using previous 
alcohol problems as additional cofactor showed that participants with previous alcohol problems (self-reported excessive drinking problem in the past) have significantly increased incidence of frailty compared to participants without previous alcohol problems, even after adjustment for several confounding factors. This variable was not included in our main analysis because only a subpopulation of participants with current alcohol use had to fulfill this question. This sub-analysis result is in accordance with a 30-year follow-up study published by Strandberg et al. [7] where alcohol use was shown to be an independent risk factor for developing frailty in old age among men who had high alcohol consumption during mid-life [7]. Previous authors have suggested that alcohol use in old age might be the result of reverse causality, whereby older adults with health problems choose to limit or reduce their alcohol use even before the presentation of frailty $[6,7,40]$. Death before old age is another important consideration influencing the relationship between alcohol use and frailty risk in shortterm follow-up studies on older adults [6, 7]. Furthermore, Kojima et al. found that high association between nondrinkers and frailty might be explained by poorer baseline health status [40]. Although the model in our study was adjusted for several baseline health status conditions, there is still possibility of residual confounding. Future studies with long-term follow-up and adjustment for various potential health-related confounding factor are warranted.

The effect of interaction between medication and alcohol use showed no significant association with frailty incidence in our study. This interaction effect is more likely associated with very specific alcohol interacting medications rather than a group of medications [41]. Further studies are needed to explore the effects of such specific alcohol-medication interactions on the risk of frailty in older adults.

The incidence of frailty in our study was $12.3 \%$ in the FI-population and 3.0\% in the FP-population, during a two-year follow-up period. Additionally, incidence of prefrailty in the FP-population was $34.4 \%$. The difference between the two measures is considerable but consistent with published literature $[39,40]$. The meta-analysis on frailty incidence reported $4.6 \%$ pooled incidence of frailty among robust older adults aged 60 years and older during a median follow-up of three years. Great majority of studies included in the meta-analysis measured frailty with frailty phenotype (FP). Studies using frailty index (FI) as diagnostic measure typically reported higher incidence of frailty. We acknowledge the differences between FP and FI concept and recognize both methods as important and leading methods for defining frailty $[2$, 42]. Therefore, we included both methods as an outcome in our study.
The study was conducted on a large population of older adults. The Survey of Health, Ageing and Retirement in Europe (SHARE) covers multiple European countries and uses objective and validated health measures. Frailty was assessed with two widely recognized methods and baseline alcohol use was evaluated using the validated AUDIT-C questionnaire. The main limitation of our study is lack of detailed data on medication use, which would enable further study of alcoholmedication interaction and the influence of specific medications on frailty risk. Due to the multidisciplinary nature of the SHARE survey, several confounding factors were adjusted for; nevertheless, potential residual confounding factors should be considered when interpreting the study results.

\section{Conclusion}

The present study explores the complex relationship between medication and alcohol use, and the incidence of frailty in older adults. Taking certain groups of medication was associated with increased incidence of frailty and pre-frailty, which might be due to either adverse effects of medication use or the underlying disease. The greatest effect size was observed in older adults taking medications for chronic bronchitis, joint pain and other pain medications, medications for coronary and other heart disease, medications for diabetes, and medications for anxiety, depression and sleep problems. In addition, association with frailty was found in older adults diagnosed with stroke, Parkinson's disease and dementia. Non-hazardous alcohol use was associated with a lower risk of frailty and pre-frailty compared to no alcohol use. Older adults with hazardous alcohol use were not significantly different from older adults with no alcohol use when using frailty phenotype as the outcome measure. The reversed association between alcohol use in old age and frailty risk might be due to reverse causality or residual confounding. The effect of interaction between medication and alcohol use showed no significant association with frailty incidence in our study.

This study informs health professionals which groups of non-frail older adults have a higher probability of progressing to frailty. In addition to reducing risk of frailty with exercise and nutrition, concerted efforts need to be made to optimize the medical condition and minimize adverse effects of medication therapy.

\section{Supplementary Information}

The online version contains supplementary material available at https://doi. org/10.1186/s12877-020-01969-y.

Additional file 1: Table A. Variables used to define Frailty phenotype (FP) from SHARE data. 
Additional file 2: Table B. Variables used to define Frailty index from SHARE data.

\section{Abbreviations}

Fl: Frailty index; FP: Frailty phenotype; SHARE: Survey of health, aging and retirement in Europe; BMI: Body mass index; ISCED: International standard classification of education; SD: Standard deviation; OR: Odds ratio;

Cl: Confidence interval; AUDIT: The alcohol use disorders identification test

\section{Acknowledgements}

This paper uses data from SHARE Waves 4, 5, and 6 (DOls: https://doi.org/10. 6103/SHARE.w4.700, https://doi.org/10.6103/SHARE.w5.700, https://doi.org/10. 6103/SHARE.w6.700), see Börsch-Supan et al. (2013) for methodological details.

The SHARE data collection was funded by the European Commission through FP5 (QLK6-CT-2001-00360), FP6 (SHARE-I3: RII-CT-2006-062193, COMPARE: CIT5-CT-2005-028857, SHARELIFE: CIT4-CT-2006-028812), FP7 (SHAREPREP: GA N²11909, SHARE-LEAP: GA N²27822, SHARE M4: GA N²61982), Horizon 2020 (SHARE-DEV3: GA N676536, SERISS: GA N654221) and by DG Employment, Social Affairs \& Inclusion. Additional funding from the German Ministry of Education and Research, the Max Planck Society for the Advancement of Science, the U.S. National Institute on Aging (U01_AG09740-13S2, P01_AG005842,P01_AG08291, P30_AG12815, R21_AG025169, Y1-AG-4553-01, IAG_BSR06-11, OGHA_04-064, HHSN271201300071C) and from various national funding sources is gratefully acknowledged (see www.share-project. org).

This work was financially supported by the Slovenian Research Agency (grant number P1-0189).

\section{Authors' contributions}

JJ contributed to design, analysis and interpretation of data and drafting the article. IL contributed to design and interpretation of data, supervision of the analysis, revising the article critically. MK contributed to design and interpretation of data, revising the article critically. All authors read and approved the final manuscript.

\section{Funding}

This work was financially supported by the Slovenian Research Agency (grant number P1-0189). The funding body had no influence on the study design, collection, analysis and interpretation of data or writing the manuscript.

\section{Availability of data and materials}

Access to the data collected and generated in the SHARE projects is provided free of charge for scientific use globally, subject to European Union and national data protection laws as well as the publicly available Conditions of Use. Access to the data is available online (http://www.share-project.org/ data-access.html) after user registration.

\section{Ethics approval and consent to participate}

The SHARE survey is subject to continuous ethics review; Waves 5 and 6 were reviewed and approved by the Ethics Council of the Max Planck Society.

\section{Consent for publication}

Not applicable.

\section{Competing interests}

The authors declare that they have no competing interests.

Received: 24 September 2020 Accepted: 16 December 2020 Published online: 07 January 2021

\section{References}

1. Dent E, Martin FC, Bergman H, Woo J, Romero-Ortuno R, Walston JD. Management of frailty: opportunities, challenges, and future directions. Lancet. 2019:394(10206):1376-86.

2. Hoogendijk EO, Afilalo J, Ensrud KE, Kowal P, Onder G, Fried LP. Frailty: implications for clinical practice and public health. Lancet. 2019;394(10206): 1365-75.
3. Morley JE, Vellas B, van Kan GA, Anker SD, Bauer JM, Bernabei R, et al. Frailty consensus: a call to action. J Am Med Dir Assoc. 2013;14(6):392-7.

4. Fried LP, Tangen CM, Walston J, Newman AB, Hirsch C, Gottdiener J, et al. Frailty in older adults: evidence for a phenotype. J Gerontol A Biol Sci Med Sci. 2001;56(3):M146-56.

5. Mitnitski AB, Mogilner AJ, Rockwood K. Accumulation of deficits as a proxy measure of aging. ScientificWorldJournal. 2001;1:323-36.

6. Kojima G, Liljas A, lliffe S, Jivraj S, Walters K. A systematic review and metaanalysis of prospective associations between alcohol consumption and incident frailty. Age Ageing. 2018;47(1):26-34.

7. Strandberg AY, Trygg T, Pitkala KH, Strandberg TE. Alcohol consumption in midlife and old age and risk of frailty: alcohol paradox in a 30-year followup study. Age Ageing. 2018;47(2):248-54.

8. Hanlon JT, Sloane RJ, Pieper CF, Schmader KE. Association of adverse drug reactions with drug-drug and drug-disease interactions in frail older outpatients. Age Ageing. 2011:40(2):274-7.

9. Armstrong JJ, Stolee P, Hirdes JP, Poss JW. Examining three frailty conceptualizations in their ability to predict negative outcomes for homecare clients. Age Ageing. 2010;39(6):755-8.

10. LaCroix AZ, Gray SL, Aragaki A, Cochrane BB, Newman AB, Kooperberg CL, et al. Statin use and incident frailty in women aged 65 years or older: prospective findings from the Women's Health Initiative observational study. J Gerontol A Biol Sci Med Sci. 2008;63(4):369-75.

11. Lohman M, Dumenci $L$, Mezuk B. Depression and frailty in late life: evidence for a common vulnerability. J Gerontol Ser B-Psychol Sci Soc Sci. 2016;71(4): 630-40.

12. Holton AE, Gallagher P, Fahey T, Cousins G. Concurrent use of alcohol interactive medications and alcohol in older adults: a systematic review of prevalence and associated adverse outcomes. BMC Geriatr. 2017;17(1):148.

13. Börsch-Supan, A. (2019). Survey of health, ageing and retirement in Europe (SHARE) wave 6. Release version: 7.0.0. SHARE-ERIC. Data set. DOl: https:// doi.org/10.6103/SHARE.w6.700.

14. Börsch-Supan, A. (2019). Survey of health, ageing and retirement in Europe (SHARE) wave 5. Release version: 7.0.0. SHARE-ERIC. Data set. DOl: https:// doi.org/10.6103/SHARE.w5.700.

15. Börsch-Supan A, Kneip T, Litwin H, Myck M, Weber G, editors. Ageing in Europe - supporting policies for an inclusive society. Berlin: De Gruyter; 2015

16. Malter F, Börsch-Supan A, editors. SHARE wave 5: Innovations \& Methodology. Munich: MEA, Max Planck Institute for Social Law and Social Policy; 2015

17. Malter F, Börsch-Supan A. SHARE wave 6: panel innovations and collecting dried blood spots. Munich: Munich Center for the Economics of Aging (MEA); 2017.

18. Borsch-Supan A, Brandt M, Hunkler C, Kneip T, Korbmacher J, Malter F, et al Data resource profile: the survey of health, ageing and retirement in Europe (SHARE). Int J Epidemiol. 2013:42(4):992-1001.

19. Opinion of the Ethics Council of the Max Planck Society on the SHARE Project. http://www.share-project.org/fileadmin/pdf_documentation/MPG_ Ethics_Council_SHARE_overall_approval_14.06.2018_en_.pdf. 2018. Accessed 24 Sept 2020.

20. Santos-Eggimann B, Cuenoud P, Spagnoli J, Junod J. Prevalence of frailty in middle-aged and older community-dwelling Europeans living in 10 countries. J Gerontol A Biol Sci Med Sci. 2009;64(6):675-81.

21. Theou O, Brothers TD, Mitnitski A, Rockwood K. Operationalization of frailty using eight commonly used scales and comparison of their ability to predict all-cause mortality. J Am Geriatr Soc. 2013;61(9):1537-51.

22. van der Linden BWA, Sieber S, Cheval B, Orsholits D, Guessous I, Gabriel R, et al. Life-course circumstances and frailty in old age within different European welfare regimes: a longitudinal study with SHARE. J Gerontol Series B-Psychol Sci Soc Sci. 2020;75(6):1326-35.

23. van der Linden BWA, Cheval B, Sieber S, Orsholits D, Guessous I, Stringhini S, et al. Life course socioeconomic conditions and frailty at older ages. J Gerontol Series B-Psychol Sci Soc Sci. 2020;75(6):1348-57.

24. Romero-Ortuno R, Kenny RA. The frailty index in Europeans: association with age and mortality. Age Ageing. 2012;41(5):684-9.

25. Searle SD, Mitnitski A, Gahbauer EA, Gill TM, Rockwood K. A standard procedure for creating a frailty index. BMC Geriatr. 2008;8:24.

26. Song X, Mitnitski A, Rockwood K. Prevalence and 10-year outcomes of frailty in older adults in relation to deficit accumulation. J Am Geriatr Soc. 2010; 58(4):681-7. 
27. Bosque-Prous M, Espelt A, Guitart AM, Bartroli M, Villalbi JR, Brugal MT. Association between stricter alcohol advertising regulations and lower hazardous drinking across European countries. Addiction. 2014;109(10): 1634-43.

28. Bosque-Prous M, Mendieta-Paredes J, Bartroli M, Brugal MT, Espelt A. Cancer and alcohol consumption in people aged 50 years or more in Europe. Alcohol Alcohol. 2018:53(3):317-24.

29. Meneses-Gaya C, Zuardi AW, Loureiro SR, Hallak JE, Trzesniak C, de Azevedo Marques JM, et al. Is the full version of the AUDIT really necessary? Study of the validity and internal construct of its abbreviated versions. Alcohol Clin Exp Res. 2010;34(8):1417-24.

30. Hanlon P, Nicholl BI, Jani BD, Lee D, McQueenie R, Mair FS. Frailty and prefrailty in middle-aged and older adults and its association with multimorbidity and mortality: a prospective analysis of 493737 UK biobank participants. Lancet Public Health. 2018;3(7):e323-32.

31. Brigola AG, Rossetti ES, Dos Santos BR, Neri AL, Zazzetta MS, Inouye K, et al. Relationship between cognition and frailty in elderly: a systematic review. Dement Neuropsychol. 2015;9(2):110-9.

32. Seppala LJ, Wermelink A, de Vries M, Ploegmakers KJ, van de Glind EMM, Daams JG, et al. Fall-Risk-Increasing Drugs: A Systematic Review and MetaAnalysis: II. Psychotropics. J Am Med Dir Assoc. 2018;19(4):371 e11-371.e17.

33. Nowak A, Hubbard RE. Falls and frailty: lessons from complex systems. J R Soc Med. 2009;102(3):98-102.

34. Mello Ade C, Engstrom EM, Alves LC. Health-related and socio-demographic factors associated with frailty in the elderly: a systematic literature review. Cad Saude Publica. 2014;30(6):1143-68.

35. Seematter-Bagnoud L, Spagnoli J, Bula C, Santos-Eggimann B. Alcohol use and frailty in community-dwelling older persons aged 65 to 70 years. J Frailty Aging. 2014;3(1):9-14.

36. Ortola R, Garcia-Esquinas E, Leon-Munoz LM, Guallar-Castillon P, ValenciaMartin JL, Galan I, et al. Patterns of alcohol consumption and risk of frailty in community-dwelling older adults. J Gerontol A Biol Sci Med Sci. 2016;71(2): 251-8.

37. Shah M, Paulson D. C-reactive protein level partially mediates the relationship between moderate alcohol use and frailty: the health and retirement study. Age Ageing. 2016;45(6):874-8.

38. Strawbridge WJ, Shema SJ, Balfour UL, Higby HR, Kaplan GA. Antecedents of frailty over three decades in an older cohort. J Gerontol Series B-Psychol Sci Soc Sci. 1998;53(1):S9-S16.

39. Cunningham SA, Mosher A, Judd SE, Matz LM, Kabagambe EK, Moy CS, et al. Alcohol consumption and incident stroke among older adults. J Gerontol Series B-Psychol Sci Soc Sci. 2018;73(4):636-48.

40. Kojima G, Jivraj S, lliffe S, Falcaro M, Liljas A, Walters K. Alcohol consumption and risk of incident frailty: the English longitudinal study of aging. J Am Med Dir Assoc. 2019;20(6):725-9.

41. Holton AE, Gallagher PJ, Ryan C, Fahey T, Cousins G. Consensus validation of the POSAMINO (POtentially serious alcohol-medication INteractions in older adults) criteria. BMJ Open. 2017;7(11):e017453.

42. Aguayo GA, Donneau AF, Vaillant MT, Schritz A, Franco OH, Stranges S, et al. Agreement between 35 published frailty scores in the general population. Am J Epidemiol. 2017;186(4):420-34.

\section{Publisher's Note}

Springer Nature remains neutral with regard to jurisdictional claims in published maps and institutional affiliations.

\section{Ready to submit your research? Choose BMC and benefit from}

- fast, convenient online submission

- thorough peer review by experienced researchers in your field

- rapid publication on acceptance

- support for research data, including large and complex data types

- gold Open Access which fosters wider collaboration and increased citations

- maximum visibility for your research: over $100 \mathrm{M}$ website views per year

At BMC, research is always in progress.

Learn more biomedcentral.com/submissions 